\title{
PRÁTICAS AVENTUREIRAS DE SKATISTAS EM ESPAÇOS URBANOS RESSIGNIFICADOS
}

Recebido em: 05/12/2013

Aceito em: 10/05/2014

Jairo Antônio da Paixão ${ }^{1}$

Universidade Federal de Ouro Preto

Ouro Preto - MG - Brasil

RESUMO: O presente estudo analisa aspectos ligados às práticas aventureiras dos skatistas que vivenciam fortes emoções em diferentes espaços urbanos. A amostra foi constituída de 28 sujeitos, praticantes de skate. A partir do método de estudo descritivoexploratório foi possível verificar que a partir das práticas do skate como prática corporal voluntária e vivenciada no tempo livre, os praticantes buscam-se ressignificar espaços urbanos em resposta às demandas e necessidades individuais e coletivas na ambiência social atual.

PALAVRAS CHAVE: Esportes. Risco. Atividades de Lazer.

\section{ADVENTUROUS PRACTICE OF SKATEBOARDERS IN RESIGNIFIED URBAN SPACES}

ABSTRACT: The present study examines aspects related practices adventurous skaters who experience strong emotions in different urban spaces. The sample consisted of 28 skateboard's practitioners. From the method of descriptive exploratory study was concluded that from the skateboard as a voluntary body practice body experienced during the free time, the practitioners try to reframe urban spaces in order to individual and collective demands and needs in current social environment.

KEYWORDS: Sports. Risk. Leisure Activities.

\footnotetext{
1 Professor Adjunto da Universidade Federal de Ouro Preto (UFOP). Coordenador do Laboratório de Estudos Pedagógicos em Educação Física (LEPEF). Docente do Programa de Pós-Graduação em Educação do Instituto de Ciências Humanas e Sociais da Universidade Federal de Ouro Preto, MG. Laboratório de Estudos Pedagógicos em Educação Física (LEPEF), Centro Desportivo da Universidade Federal de Ouro Preto, Minas Gerais.
} 


\section{Introdução}

O esporte configura-se como um dos maiores fenômenos socioculturais em escala mundial nesta contemporaneidade. Tamanha é sua abrangência que o esporte evidencia não somente a forma como a sociedade se organiza, como as contradições existentes em seu cotidiano (PAIXÃO; TUCHER, 2010). Dentre a multiplicidade de elementos que delineiam o fenômeno esporte, destaca-se um permanente processo de evolução, surgindo ininterruptamente significados e ressignificados para a sua prática ao longo dos tempos.

Nesse contexto de evolução, observa-se nos estudos empreendidos por Coiceiro (2007) que, a partir da transição paradigmática, da modernidade para a pósmodernidade, surgem de forma ininterrupta novas práticas corporais, entre elas os esportes radicais. Trata-se de uma vertente esportiva que elegeu os diferentes ambientes naturais (terrestre, aéreo e aquático) como lócus privilegiado para a sua manifestação.

Os esportes radicais surgem a partir de novos paradigmas centrados na (re)aproximação com a natureza, na auto realização, no lazer e na melhoria da qualidade de vida, os quais buscam substituir os de competição, rendimento e esforço pela incerteza, risco e liberdade (COICEIRO, 2007; COSTA, 2000; MARINHO, 2007; PASSOS, 2004; PAIXÃO; TUCHER, 2010). A vivência dessas práticas corporais, como acrescenta Passos (2004), experimentadas, pelo indivíduo, no tempo destinado ao lazer não valorizam, a princípio, nenhuma forma de egocentrismo, e sim uma nova forma de exaltação da autonomia e do tempo de viver por viver, num caminhar sem rumo, a vislumbrar possibilidades de distanciamento da rotina diária.

Assim, a prática das modalidades de esportes radicais manifesta-se impulsionada pelo desejo de se experimentar algo novo, singular, específico, perpassado por emoções 
prazerosas, utilizando-se da tecnologia para o campo da recreação e do lazer. Como modalidade que se insere nos esportes radicais, as informações ressaltadas coadunam com aquelas experienciadas e buscadas pelos praticantes de skate.

A origem do skate, devido à falta de registros precisos, permite várias versões. De acordo com Brooke (1999), seu desenvolvimento nos EUA estaria relacionado a um meio de locomoção entre os jovens a partir da fixação de rodinhas de ferro e/ou borracha em caixas de madeiras usadas para o transporte de frutas entre as décadas de 1920 e 1940. Gebara e Honorato (2004) pontuam que, mais tarde, essa forma de transporte foi associada à prática do surf recebendo a denominação inicial de sidewalk surfing. No entanto, como afirma Brandão (2008), a denominação que prevaleceu nos EUA para o skate foi skateboard, expressão que se traduzida em sua forma literal para o português possivelmente venha a significar algo como "tábua com rodas".

O desenvolvimento do skate enquanto modalidade se deu de forma efetiva na década de 1970, com a adaptação e introdução do poliuretano na construção das rodas de skate, as quais antes eram produzidas somente com borracha, ferro ou argila. Essa nova tecnologia acarretou uma reviravolta na história dessa atividade, pois com o poliuretano os skates passaram a ser mais velozes e aderentes ao asfalto, e passou a conquistar muitos adeptos, o que possibilitou o aparecimento de inúmeras manobras (BRANDÃO, 2008).

No Brasil, o desenvolvimento do skate encontra-se atrelado à história do surf no Rio de Janeiro, no final da década de 60. De acordo com Bolota (2001), os surfistas cariocas descobriram essa modalidade esportiva através de anúncios veiculados por uma revista norte-americana chamada surfer. Ainda na década de 1960, era conhecido por "surfinho" pelo fato de as pessoas associarem-no com o surf. O autor complementa que 
no início, como não havia skates ou "surfinhos" para vender no Brasil, os surfistas cariocas o improvisavam arrancando os eixos e rodas dos patins e os fixando numa madeira qualquer, cortando-a no formato que viam nas páginas das citadas revistas norte-americanas. Essa situação permaneceu até por volta de 1974, quando os primeiros skates passaram a ser vendidos no Brasil em lojas nos shopping centers nas capitais brasileiras.

Percebida, muitas vezes, como uma atividade relacionada às pessoas desocupadas e transgressoras às normas sociais, parece prevalecer uma visão estereotipada e preconceituosa sobre os praticantes. Um exemplo dessa percepção encontra-se, por exemplo, no episódio ocorrido com os skatistas que foram proibidos de praticar o skate nos espaços urbanos da cidade de São Paulo, em 1988, por determinação do prefeito Jânio Quadros. Esta medida foi entendida pelos skatistas como a maior repressão e abuso de poder já vistos contra a prática do skate (BOLOTA, 2001).

Atualmente, dentre as atividades de aventura, de acordo com Pimentel e Saito (2010), o skate configura-se dentre as mais praticadas e conhecidas, se manifestando como um produto próprio da modernidade e faz aproximações de aprendizagens e práticas, no campo do lazer, competitivo e educacional (PEREIRA; CARCERONI; MENEZES, 2008). Nesse sentido, as práticas aventureiras dos grupos skatistas com manobras 'prá lá' de radicais, compõem o cenário das pequenas, médias e grandes cidades que, em sua maioria, aglomeram-se e fazem uso de espaços urbanos como parques, asfaltos, praças, estacionamentos de prédios comerciais e em locais com menor movimento de carros e/ou transeuntes, que em seu tempo livre, realizam uma verdadeira celebração ao risco, e a ousadia na paisagem urbana. 
Estes grupos são denominados skatistas urbanos e, por sua vez, formam uma espécie de tribo urbana conforme evidencia Maffesoli (1995) que, distinta no âmbito social, destaca-se pela similitude de hábitos, atitudes, vestimentas, linguagens e formas expressivas e corporais. Seguramente, como comprovam estudos na área da Antropologia e Sociologia (MAUSS, 2005; GEERTZ, 1989; MAFFESOLI, 1995; 2001; 2006), as manifestações corporais humanas como é o caso dos skatistas urbanos, apresentam-se em íntima profusão aos contextos sociais e culturais em que se inserem o homem.

Procedendo a uma análise do assunto, buscou-se com esse estudo, analisar as práticas aventureiras dos skatistas urbanos que buscam vivenciar fortes emoções em espaços urbanos de uma cidade interiorana no estado de Minas Gerais.

\section{Metodologia}

Esta pesquisa caracterizou-se como um estudo descritivo-exploratório (DRAKE; MILLER, 1969; MALHOTRA, 2000; MATTOS; ROSSETO; BLECHER, 2004). O grupo amostral totalizou em 28 sujeitos, praticantes de skate nos centros urbanos da cidade de Muriaé, MG. Ainda que a seleção desses sujeitos tenha acontecido de forma aleatória, o grupo amostral compreendeu-se em sua totalidade por indivíduos do sexo masculino, com média de idade de aproximadamente 17 anos. Quanto ao nível de instrução, em sua quase totalidade, os sujeitos detinham a educação básica e apenas $46 \%$ encontravam atuando profissionalmente, nos diferentes setores do comércio local, bem como na informalidade. Para a coleta dos dados, foram empregadas as técnicas de observação, filmagens e entrevista semiestruturada no período compreendido entre os meses de fevereiro a maio de 2012 nos espaços urbanos utilizados pelos mesmos para a 
prática da referida prática corporal. A técnica de observação (SAMPIERI; COLLADO; LUCIO, 2013) consistiu no registro sistemático do comportamento e/ou conduta manifesta pelos skatistas nos espaços urbanos ocupados pelos mesmos nas vivências da referida prática corporal. As filmagens foram realizadas concomitantes às observações. A entrevista semiestruturada fundamentou-se nos estudos de Spradley (1979) que assinala a entrevista com características etnográficas como sendo um evento discursivo, o qual por sua vez pode ser descrito pelo modo de conduzir alguns diálogos em ocasiões ou encontros sociais. Nessa perspectiva, o autor entende as entrevistas como uma série de conversações entre amigos, dentro das quais o pesquisador suavemente introduz novos elementos para ajudar os informantes a responder como informantes. Os eixos norteadores da entrevista compreenderam os motivos que influenciaram na adesão pelo skate; as sensações experimentadas no momento da prática; a frequência com que pratica a modalidade; os procedimentos e equipamentos que visam à segurança do praticante; as dificuldades para a prática da modalidade (NUNOMURA, 1998; SABA, 2001; SANTOS; KNIJNIK, 2006).

$\mathrm{Na}$ análise dos dados, utilizou-se a técnica de análise de conteúdo que se refere a um conjunto de técnicas de análise das comunicações que visa obter, por procedimentos sistemáticos e objetivos de descrição do conteúdo das mensagens, indicadores quantitativos ou não que permitam a inferência de conhecimentos relativos às condições de produção/recepção (variáveis inferidas) destas mensagens (BARDIN, 2006). Após análise interpretativa dos dados, esses foram categorizados e quantificados a partir da frequência de ocorrência no discurso dos sujeitos. Na análise dos dados foi utilizado o programa N-Vivo 9, versão em português. 
Explicou-se aos entrevistados acerca do estudo, seu propósito, deixando-os a par dos objetivos do mesmo. Os critérios de inclusão foram indivíduos que praticavam skate em áreas urbanas da cidade de Muriaé, Minas Gerais e assinatura do Termo de Consentimento Livre e Esclarecido (TCLE). Os critérios de exclusão foram recusa da assinatura do TCLE e o não interesse dos sujeitos em participar da investigação.

\section{Resultados e Discussão}

De início, questionou-se aos entrevistados a despeito dos motivos que contribuíram para a sua adesão ao skate como prática desportiva.

Gráfico 1 - Motivos que contribuíram para adesão ao skate como prática esportiva.

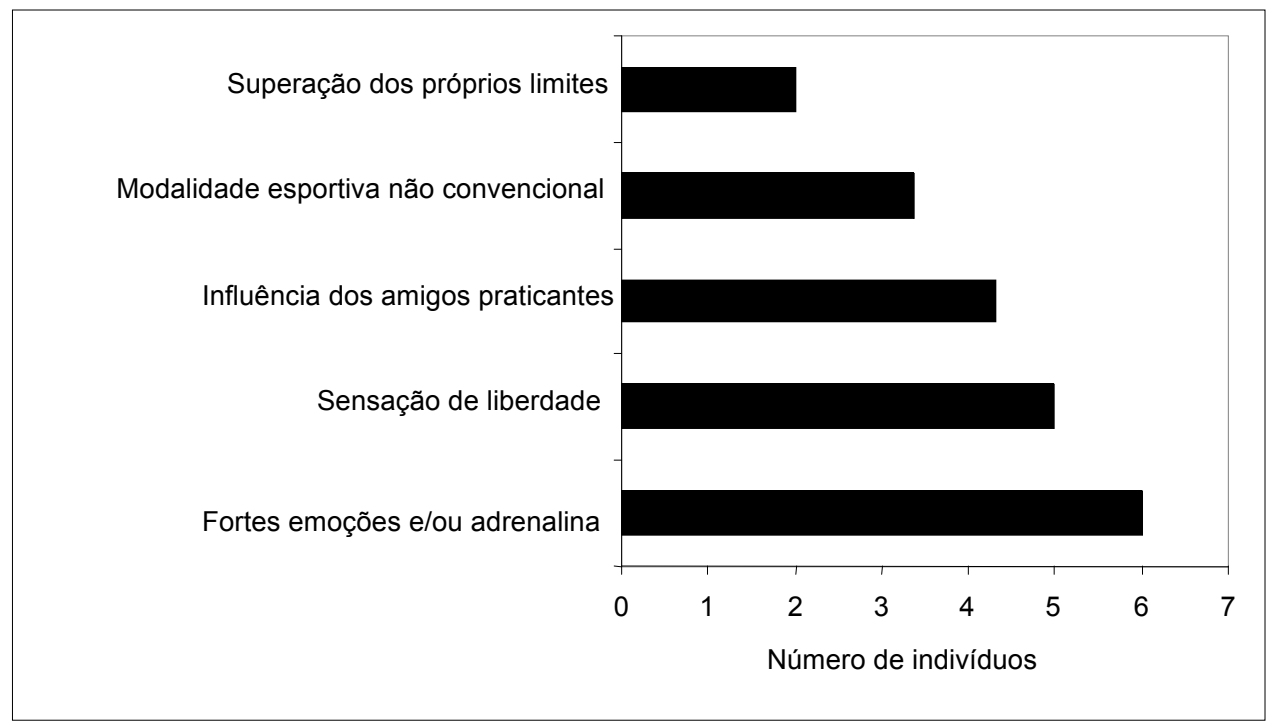

Como mostra o Gráfico 1, as respostas apresentaram-se de forma diversificada nas quais os praticantes alegaram motivos como 'busca por fortes emoções e/ou adrenalina', 'velocidade', 'sensação de liberdade' e 'superação dos próprios limites', como se pode perceber em alguns depoimentos: "[...] o skate me faz sentir livre, leve e solto todo o momento em que me encontro sobre essas quatro rodas [...]". "Posso brincar com a velocidade, me jogar de um lado para outro. Sensação de liberdade total [...]”. “Nós, do grupo de skate, buscamos um objetivo único: adrenalina pura”. Soma- 
se ainda, depoimentos nos quais os entrevistados elucidam o fato do skate configurar-se como uma modalidade esportiva e, que, por sua vez, diferencia-se dos esportes tradicionais como o voleibol, futebol e handebol, os quais foram exaustivamente vivenciados nas aulas de educação física no decorrer da educação básica.

Os motivos que levam o indivíduo a realizar ações podem se manifestar de forma intrínseca ou extrínseca (TRESCA; DE ROSE, 2000). Os motivos intrínsecos resultam da vontade própria do indivíduo e podem estar relacionados às necessidades pessoais de afirmação em um determinado grupo social, esportivo ou familiar, sucesso pessoal e profissional dentre outros (VAN RAALTE; BREWER, 2011; TRESCA; DE ROSE, 2000). Já os motivos extrínsecos estão segmentados aos fatores externos e atingíveis por meio de tarefas e, acima de tudo, são tidos como recompensáveis por sinais positivos e/ou negativos socialmente reconhecíveis (VAN RAALTE; BREWER, 2011; HORN, 2002; SERPA, 1992; TRESCA; DE ROSE, 2000). Como exemplos de motivos intrínsecos e extrínsecos ressaltam-se alguns depoimentos como: “[...] as pessoas sempre param para ver nossas manobras radicais aqui nesse estacionamento [...] isso nos faz sentir gente importante, astros das pistas no skate”. "[...] as pessoas que passam por aqui parecem que gostam de assistir a gente fazer essas manobras [...]”. "O skate faz parte de minha vida [...]".

A teoria do flow-feeling desenvolvida por Csikszentimihalyi (1975) contribui para o entendimento sobre 'fortes emoções e/ou adrenalina', 'velocidade', 'sensação de liberdade', e 'superação dos próprios limites', relatados pelos praticantes como motivos que os levam a praticar o skate. Originalmente, esta teoria foi desenvolvida para explicar a popularidade de certas atividades físicas que apresentam características como desgaste, risco e certo grau de dificuldade que, por sua vez, exigem do indivíduo 
considerável persistência (CATER, 2006). A experiência do fluir configura-se como aspecto comum aos diferentes interesses culturais do lazer (HENDRY et al., 1996). No caso do skate, a experiência do fluir parece intensificar-se como efeito de aspectos considerados pelos estudiosos do lazer em sua caracterização como, por exemplo, a escolha voluntária de caráter desinteressado e espontâneo pelo sujeito dos diferentes interesses culturais vivenciados nos momentos disponíveis, livres das ocupações profissionais, escolares, politicas, religiosas, familiares e, ainda, aquelas que são realizadas em semelhante perspectiva no dia a dia (MARCELLINO, 2006). Essa situação encontra-se presente nas falas dos praticantes, como por exemplo, “[...] precisamos praticar sempre. Para o skate não pode existir tempo ruim". "As quedas fazem parte desse esporte. Aqui, não há ninguém que não tenha marcas pelo corpo afora, provocadas pelo skate [...]”. “[...] a gente cai, levanta e continua o show. É assim mesmo, a gente não desiste nunca”. "O skate tá no sangue da gente [...]”.

A 'influência dos amigos praticantes' se constitui como importante motivo para diferentes opções pelo indivíduo nos diferentes setores da vida. Influência essa, que pode exercer significâncias primárias do ponto de vista positivo e/ou negativo na adoção de práticas corporais. Tamanha é a relevância desse tipo de influência na aderência a uma dada modalidade esportiva que esta tem sido uma temática amplamente discutida pela Psicologia do esporte (BECKER, 2004; DE ROSE, 2009). Ainda que o skate seja reconhecido esporte, esta situação, segundo depoimentos, não se mostra de forma semelhante tal e qual ocorre com a influência de amigos e familiares quando se trata da adesão por modalidades esportivas mais tradicionais. Em outras palavras, o incentivo, em sua maioria, não foi detectado nos depoimentos dos skatistas entrevistados, tanto por parte de seus familiares, quanto de amigos não praticantes. Essa 
situação fornece indícios que a prática do skate ainda sofre discriminação, não dispondo ainda de status, a exemplo de outras modalidades esportivas como o futebol, voleibol, basquete e outras que, após passarem pelo processo de esportivização (GONZALEZ; FENSTERSEIFER, 2005) e difusão por meio da mass media na ambiência social.

Os praticantes relataram ainda o fato de o skate se configurar como uma modalidade diferente de modalidades esportivas clássicas, comumente privilegiadas nas aulas de Educação Física. Nessa perspectiva, Bauman (1999) chama a atenção para o fato de que vive-se uma fase de complexa mudança, com perdas de valores e estilos de vida, vazio existencial e preocupações permanentes. Presencia-se um momento de busca por "algo" desconhecido e indefinido, o que apresenta correlações com o interesse por parte das pessoas no que concerne às práticas corporais, pela experimentação de modalidades de esporte de aventura e/ou radicais (MARINHO, 2007). Dito de outra maneira, nas palavras de Betrán e Betrán (1995), as atividades que propiciam a aventura representam formas diferenciadas de o indivíduo relacionar-se com o seu corpo, com técnica e recordes, convertendo-se em elementos sociais que produzem e acompanham o pensamento coletivo, criando, como observa Costa (2000), uma verdadeira renovação simbólica e de signos no imaginário esportivo atual.

Termos como adrenalina, fortes emoções e superação passaram a fazer parte da linguagem cotidiana daqueles que se entregam à aventura e aos momentos em que vivenciam a prática do skate, característica comum que fundamenta as diferentes modalidades de esporte de aventura (PAIXÃO et. al., 2010).

Dentre as sensações percebidas no momento em que desenvolvem as manobras radicais, os entrevistados, em sua totalidade, mencionaram uma miscelânea de sensações ligadas ao risco, adrenalina, fortes emoções, velocidade e liberdade. Ressalta- 
se uma das falas que traduz as sensações acima descritas: “[...] certo frio na barriga. Surge apenas uma pergunta: 'será que consigo?'. Um alívio após as manobras de sucesso. Mantém a vontade de continuar sempre”.

Ainda que a sensação de liberdade e as fortes emoções compensem o risco com que os praticantes se encontram frente a frente no momento da prática, estes não podem ser interpretados como irresponsáveis ou suicidas, e sim como pessoas que gostam de vivenciar situações de risco e excitação que lhes causem prazer nos momentos disponíveis em que buscam vivenciar atividades de lazer (ELIAS; DUNNING, 1992). Esses atores se lançam em situações que lhes permitem calcular os riscos e lhes dão condições de controlar o imponderável naquele momento. Le Breton alerta sobre a atitude contra-fóbica, em que um indivíduo, em vez de evitar ou fugir de situações de risco, lança-se em sua direção (LE BRETON, 2000). Trata-se de uma maneira refinada de esses indivíduos enfrentarem o medo, dissipando-o e sentindo a provisória sensação agradável de tê-lo dominado.

Com relação à frequência com que praticam a referida modalidade, os entrevistados, em sua maioria, alegaram dedicar-se principalmente nos momentos em que se encontram livres das atividades relacionadas ao trabalho, à escola ou à universidade. Em seus depoimentos, esses sujeitos, em sua maioria, alegaram que a prática do skate configura-se como a principal e, em alguns casos, como a única prática corporal desenvolvida pelos mesmos nos momentos livres das obrigações diárias.

Quando se questionou sobre "procedimentos e equipamentos que visam à segurança do praticante', as afirmações apontaram para uma situação em que, apesar do risco presente na prática do skate, raramente são adotados equipamentos de segurança além do próprio skate. Ao discutir as condutas do risco, Le Breton afirma que as experiências 
adquiridas e a integração gradual das técnicas minimizam as ameaças ou as circunscrevem em pontos onde se exerce vigilância. A menor desatenção pode causar sérios problemas (LE BRETON, 2000). Há de se considerar ainda que as referidas modalidades, estimuladas pelo desenvolvimento da pesquisa científica, tanto na melhoria do desempenho técnica como na produção de material, possibilitam cada vez mais ao praticante vivenciar as fortes emoções dentro de uma margem de controle do risco em que se coloca a cada vez que se atira numa manobra radical.

Dentre as dificuldades relatadas pelos skatistas para a prática da modalidade, destacou-se a falta de espaços específicos no meio urbano. "“...] a gente transforma qualquer ponto da cidade em pista para fazer as manobras. O skatista precisa ter muita criatividade e imaginação [...]”. "[...] sabemos de áreas onde a prefeitura poderia construir pistas para o skate. Eles não têm interesse pelo skate [...]”. Das observações, foi possível depreender que, em decorrência da referida dificuldade, ocorre um processo de ressignificação dos espaços públicos. Bancos de jardins e parques, escadas, corrimões e estacionamentos de prédios públicos e supermercados se transformam, nos finais de semana, em verdadeiras pistas para a realização de manobras radicais por esses aventureiros. Em meio às proibições da apropriação desses espaços por parte dos órgãos públicos e proprietários, esses skatistas resistem e/ou impõem sua presença na paisagem urbana.

Ainda que a prática do skate analisada nesse estudo apresente características comuns àquelas consideradas como experiências de lazer, verifica-se o skate tal e qual ocorre nos espaços urbanos mencionados, parece subverter uma lógica objetivada e instrumental impostos pelos moradores da cidade que se encontram alheios a essa prática corporal. Foi possível observar certo desconforto e incômodo nos transeuntes 
pela presença dos skatistas nesses locais. Raramente se detectava um olhar de admiração pela ousadia, coragem e domínio de técnicas concretizadas nas manobras realizadas por integrantes da tribo de skatistas. Acima de tudo, como afirma Gomes (2008), a efetivação do lazer no meio social demanda uma série de requisitos que incluem desde discussões sobre sua abrangência como componente cultural, de políticas públicas, espaços e equipamentos para sua realização. Apesar do número significativo e recorrência da prática do skate naqueles espaços ressignificados, pareceu que a mesma ainda estava longe do merecimento da atenção do poder publico daquela cidade para sua implementação. Ao se discutir os diferentes aspectos que perpassam o lazer, Marcellino (2000) discute com muita propriedade as barreiras socioculturais ao lazer que, na maioria das vezes, tem como pano de fundo a questão econômica. Dentre os tipos de barreiras apontados pelo autor como gênero, faixa etária, nível de escolarização, violência, precariedade dos meios de transporte públicos que dão acesso aos centros urbanos, onde, na maioria das vezes, se concentram os equipamentos específicos de lazer, pode-se afirmar que o estereótipo parece ainda ocupar posição destacada entre os demais tipos de barreiras socioculturais no caso do skate.

A prática do skate analisada nesse estudo caracteriza-se como um interesse físico esportivo que, por sua vez, encontra-se diretamente atrelada ao processo de urbanização. Sobretudo, o skate no âmbito das práticas corporais de movimento encontra-se em um ininterrupto processo histórico de construção e reconstrução pela humanidade, o que desponta possibilidades de mudanças.

\section{Conclusões}


As modalidades de esportes radicais vêm despertando a atenção das pessoas, aumentando-lhes a popularidade em todo o mundo. Termos como adrenalina, superação e vertigem passaram a fazer parte da linguagem do cotidiano, trazendo à mente as sensações fortes, as imagens de risco e emoções vividas nessas atividades.

No contexto desta modalidade, o segmento dos skatistas urbanos surge como uma derivação da mesma, a qual pela sua incidência na paisagem urbana instiga pesquisas de diversas naturezas. Desta forma, verifica-se um progressivo aumento e popularização desta prática corporal por diferentes setores da sociedade como, por exemplo, pela mass media seja em programas televisivos de natureza esportiva e novelas destinadas ao o público jovem.

Acrescenta-se, pelas observações realizadas, que os grupos juvenis que se formam em torno da prática do skate, buscam e compartilham vivências instigantes através das manobras radicais, junto aos espaços públicos ressignificados para essa prática corporal. Desta forma, as ruas, os estacionamentos de supermercados, calçadas e corrimões de prédios públicos e privados configuram-se como equipamentos não específicos do lazer que, por sua vez, proporcionam aos praticantes do skate as vivências aventureiras dessa prática corporal no meio urbano. Retomando a expressão metafórica "tribos urbanas", observou-se, junto a esses aventureiros, um movimento de compartilhamento mútuo das técnicas necessárias à realização das manobras, dos riscos, das fortes emoções e outras sensações proporcionadas pela modalidade. Tal comportamento parece contestar o individualismo percebido nas relações sociais que se estabelecem na contemporaneidade.

Ao se analisar o skate na perspectiva de uma prática corporal vivenciada nos momentos disponíveis, de maneira espontânea e desinteressada, chama a atenção o 
descompasso existente entre o interesse do segmento juvenil da população e a disposição dos espaços destinados à sua prática no ambiente urbano de uma cidade interiorana no estado de Minas Gerais.

A análise desenvolvida nesse estudo sobre a prática do skate no meio urbano leva, indubitavelmente, à sua consideração como uma manifestação genuína do lazer e como tal, demanda uma série de requisitos que incluem desde discussões sobre a sua abrangência como componente cultural, bem como de políticas públicas e setoriais visando a sua efetiva implementação. O movimento de ressignificação dos espaços urbanos fornece indícios pontuais da existência de uma demanda da criação de espaços públicos no meio urbano para a vivência desse interesse cultural do lazer.

\section{REFERÊNCIAS}

BARDIN, L. Análise de conteúdo. Lisboa: Edições 70, 2006.

BAUMAN, Z. O mal-estar da pós-modernidade. Rio de Janeiro: Jorge Zahar, 1999.

BECKER, J. Psicologia aplicada à criança no esporte. Novo Hamburgo: Edelbra, 2004.

BETRÁN, A. O.; BETRÁN, J. O. Propuesta de un classificación taxonômica de las actividades físicas de aventura em la natureza. Marco conceptual y análisis de los critérios elegidos. In: Dossier Las Actividades Físicas de Aventura en la Natureza: análisis sociocultural. Apunts: Educación Física y Deportes, v. 41, p.108-123, 1995.

BOlOTA, F. Anos 80. In.: BRITTO, E. (Org.). A onda é dura: 3 décadas de Skate no Brasil. São Paulo: Estação Liberdade, 2001.

BRANDÃO, L. Entre a marginalização e a esportivização: elementos para uma história da juventude skatista no Brasil. Revista de História de Esporte, v. 10, n. 2, p.115-129, 2008.

BROOKE, M. The concrete wave: the history of skateboarding. EUA: Warwick House Publishing, 1999.

CATER, C.I. Playing with risk? Participant perceptions of risk and management implications in adventure tourism. Tourism Management, v. 27, p.317- 325, 2006. 
COICEIRO, G. A. O imaginário social de aventureiros do extremo: o universo simbólico dos praticantes de provas de ultra-resistência. 298 f. Tese (Doutorado) Programa de Pós-Graduação em Educação Física, Universidade Gama Filho, Rio de Janeiro, Brasil, 2007.

COSTA, V. L. M. Esportes de aventura e risco calculado na montanha: um mergulho no imaginário. São Paulo: Manole, 2000.

CSIKSZENTMIHALYI, M. Beyound boredom and anxiety. San Francisco: JosseyBass, 1975.

DE ROSE, J. D. Esporte e atividade física na infância e adolescência: uma abordagem multidisciplinar. Porto Alegre: Artmed, 2002.

DRAKE, J. E.; MILLER, F. J. Marketing research: intelligence and management. Stranton Pa: International Textbooks, 1969.

ELIAS, N.; DUNNING, E. A busca da excitação. Lisboa: Difel, 1992.

GEBARA, A.; HONORATO, T. Esportes Radicais e Tecnologização. In: CONGRESSO CIENTIIFICO LATINO-AMERICANO DE EDUCAÇÃO FÍSICA DA UNIMEP, 3, 2004. Anais... Piracicaba, 2004.

GEERTZ, C. A interpretação das culturas. Rio de Janeiro: Guanabara Koogan, 1989.

GOMES, C. L. Lazer, trabalho e educação: relações históricas, questões contemporâneas. 2. ed. Belo Horizonte: UFMG, 2008.

GONZALEZ, F. J.; FENSTERSEIFER, P. E. Dicionário crítico de Educação Física. Ijuí: Unijuí, 2005, p. 209.

HENDRY et al. Young people's leisure and lifestyles. New York, USA: Routledge, 1996.

HORN, T. S. Advances in Sport Psychology. Champaign: Human Kinetics, 2002.

LE BRETON, D. Passions du risque. Paris: Métailié, 2000.

MAFFESOLI, M. Sobre o nomadismo: vagabundagens pós-modernas. Rio de Janeiro: Recorde, 2001.

MAFFESOLI, M. Os tempos das tribos: o declínio do individualismo nas sociedades de massa. 4. ed. Rio de Janeiro: Forense, 2006.

MAFFESOLI, M. A contemplação do mundo. Porto Alegre: Artes e Ofícios, 1995.

MALHOTRA, N. K. Pesquisa de marketing: uma orientação aplicada. Porto Alegre: Bookman, 2000. 
MARCELLINO, N. C. Estudos do lazer: uma introdução. 4. ed. Campinas: Autores Associados, 2006.

MARCELLINO, N. C. Lazer e educação. 6. ed. Campinas: Autores Associados, 2000.

MARINHO, A. Lazer, natureza e aventura: compartilhando emoções e compromissos. In: ALMEIDA, A. P. C.; L. P. COSTA, (Org.) Meio ambiente, esporte, lazer \& turismo. Rio de Janeiro: Editora Gama Filho, 2007.

MATTOS, M. G.; ROSSETO, J. R.; BLECHER, S. Teoria e prática da metodologia da pesquisa em educação física: construindo sua monografia, artigo científico e projeto de ação. São Paulo: Phorte, 2004.

MAUSS, M. Sociologia e antropologia. 2. ed. São Paulo: Cosac Naify, 2005.

NUNOMURA, M. Motivos de adesão à atividade física em função das variáveis, idade, sexo, grau de instrução e tempo de permanência. Revista Brasileira de Atividade Física e Saúde. v.3, n. 3, p. 45-58, 1998.

PAIXÃO, J. A.; TUCHER, G. Risco e aventura por entre as montanhas de Minas: a formação do profissional de esporte de aventura. Revista Pensar a Prática, v.13, n. 3, p. 11-19, 2010.

PAIXÃO, J. A. et. al. Práticas aventureiras e situações de risco no voo livre: uma análise a partir do conceito de redoma sensorial. Motriz, v.16 n.3 p.672-58, 2010.

PASSOS, K. C. M. Caminhando nas trilhas do reencantamento da natureza: uma ecologia do corpo sagrado e errante. 353 f. Tese (Doutorado) - Programa de PósGraduação em Educação Física. Universidade Gama Filho, Rio de Janeiro, 2004.

PEREIRA, D. W.; CARCERONI, D. S.; MENEZES, E. O skate em São Bernardo do Campo: In: CONGRESSO BRASILEIRO DE ATIVIDADES DE AVENTURA: conquistando novas vias, 2008. Anais... Santa Teresa, Espírito Santo, 2008.

PIMENTEL, G. G. A.; SAITO, C. F. Caracterização da demanda potencial por atividades de aventura. Revista Motriz, v.16, n.1, p.152-161, 2010.

TRESCA, R. P.; DE ROSE, J. D. Estudo comparativo da motivação intrínseca em escolares praticantes e não praticantes de dança. Revista Brasileira de Ciência e Movimento. v.1, n. 2, p. $9-13,2000$.

SABA, F. K. F. Aderência à prática do exercício físico em academias. São Paulo: Manole, 2001.

SAMPIERI, R. H.; COLLADO, C. F.; LUCIO, M. D. P. B. Metodologia de pesquisa. 5. ed. São Paulo: Artmed, 2013.

SANTOS, S. C.; KNIJNIK, J. D. Motivos de adesão à prática de atividade física na vida adulta intermediária. Revista Mackenzie de Educação Física e Esporte. v.1, n. 2, p.23-34, 2006. 
SERPA, S. Motivação para a prática desportiva: Validação preliminar do questionário de motivação para as actividades desportivas. In: SOBRAL, F. A. Marques (Org.) FACDEX: Desenvolvimento somato-motor e factores de excelência desportiva na população escolar português. v.2, n.3, p.89-97, 1992.

SPRADLEY, J. P. The ethnographic interview. Florida: Harcourt Brace Jovanovich, 1979.

VAN RAALTE, J. L.; BREWER, B. W. Psicologia do esporte. São Paulo: Santos Editora, 2011.

\section{Endereço do Autor:}

Jairo Antônio da Paixão

Avenida JK, 677, apt. 302 bloco 4 - Bairro Bauxita

Ouro Preto, MG - CEP 35400-000

Endereço Eletrônico: jairopaixao2004@yahoo.com.br 